\title{
Embracing the Unknown in Radiology Education
}

\author{
Christian W. Cox, MD, Richard B. Gunderman, MD, PhD \\ I don't want a poem that I can tell was written toward a good ending. ... You've got to \\ be the happy discoverer of your ends. \\ —Robert Frost
}

Most radiology education—especially the learning that takes place around high-stakes tests such as the American Board of Radiology exams—is focused on the known. The learner or candidate may not know the answer to a particular question, but the entire enterprise is based on the presumption that someone-an expert in the field, a faculty member, or an examination question writer-does.

In the setting of the known, the learner's objective is generally straightforward-to anticipate what the teachers know, or at least what they think they know. In theory, every wellwritten multiple-choice question has one correct response and several incorrect ones, often referred to as "distractors," and the best learners are the ones who ferret out the correct responses most reliably.

We believe that this model of education—focusing on the known—has important limitations that deserve careful exploration. We'd all agree that many questions have correct answers and that knowing the right from the wrong has clear benefit in many situations. In fact, knowing the right answer may make a big difference in a patient’s care or even save a life.

This is the author's manuscript of the article published in final edited form as:

Cox, C. W., \& Gunderman, R. B. (2016). Embracing the Unknown in Radiology Education. Journal of the American College of Radiology, 13(9), 1132-1134. https://doi.org/10.1016/j.jacr.2016.05.011 
In many cases, the "right” answer is but a limited truth, and a truly well-educated and highly competent physician knows more. For example, a physician certified in cardiac life support may understand the resuscitation algorithm and employ it perfectly in practice, yet fail to recognize the underlying pathology that led to cardiopulmonary arrest and thus overlook an opportunity to save a life.

Moreover, there are many questions that do not have clearly correct answers, and often these questions are at least as important as the ones to which the answers are known. All the questions to which we think we have the answers today were once of this unknown nature-not only weren't the answers known, but the questions themselves were once novel.

If learners operate with the expectation that every question—or at least every good question - is of the kind that has a right answer, they are likely to develop undesirable habits of mind that blunt their own curiosity and appetite for exploration [1]. To an often unrecognized degree, we need future radiologists who not only know the right answers but ask good questions.

Simply put, we need to teach the unknown — the fact that all radiologists, even the leaders in the field, encounter questions every day to which they do not know the answer. Consider, for example, the often unquestioning use of the term “idiopathic.” To recognize and address only questions to which the correct answer is known would be to stop expanding the envelope of radiological knowledge.

One means of doing so is to present cases to which the correct answer is unknown. Better yet, educators can show cases that baffle them in some way. A case and a conference are not a failure just because people leave without knowing the correct answer. In fact, the value of such 
open-ended questions and subsequent discussion has been long recognized across most educational domains [2, 3, 4].

Another approach is to ask learners to bring cases or experiences that have generated questions to which they would like to have an answer. Such an exercise aims not at getting to an answer that the educator already knows, but to see how the educator handles the unknown. It can also foster a collaborative relationship between learners and educators.

Attending physicians know a lot, but they do not know everything—in fact, far from it. Only by encountering the limits of our own knowledge can we identify questions worth exploring further. By "explore” we mean not looking them up in a book, but trying to figure out an approach to understand them better and begin to get some answers.

Of course, this approach places new demands on educators. For one thing, it means that the educator is no longer presumed to be omniscient. Not only do educators have a limit to their knowledge of right answers, but they also don’t even know all the good questions. A major benefit to this approach is its tacit recognition that the learner will soon be the educator's peer.

The shift toward teaching the unknown also requires the development of a resource that some educators may find too disconcerting to tolerate-namely, the virtue of humility. It requires the recognition that in comparison to all that remains to be discovered, even the most learned have a great deal to learn and will never be the keepers of all truth.

What we are talking about here is not only acknowledging unknowns, but also forming a positive attitude toward the unknown. Instead of regarding the unknown as a threat to our 
expertise and our self-image, we need to begin to regard it as an opportunity—an opportunity for the shared pursuit of discovery between learners and educators.

In some ways, teaching the unknown breaks down some of the hierarchy between "those who know" and "those who don't," leveling the playing field in such a way that both become coinquirers. In some cases, educators may learn more than learners from the experience—-not because they are learning from learners, but because they are learning with them.

Embracing the unknown may prove challenging for learners, many of whom have become accustomed since childhood to being tested on questions with clear right and wrong answers, always assessing their performance by their ability to get them all right. There is something comforting about knowing that there are right and wrong answers, and always knowing how well you scored.

To repeat, however, such expectations — taken to the extreme—can produce learners who are incurious, intolerant of uncertainty, and unable to cope with the true complexity of contemporary radiological practice. To be completely developed as professionals, they need to learn the value of saying, "I don’t know, but here is a way we might find out."

Just as teaching the unknown requires a kind of humility on the part of educators and learners, it also requires something akin to courage. It takes guts to admit that you don't know. In our experience, the wisest and most highly respected colleagues are the ones who offer up such admissions most frequently.

Those who cannot admit the limits of their own knowledge fall victim to pretending that they know something they really don't, simply to save face. The intellectual integrity of the field 
hinges in part on the resistance of radiologists to sustaining a façade of perfection, even and perhaps especially when it is most tempting to do so.

Confronted with a seemingly ill-formed question about the unknown, an educator might respond with, “I don’t know the answer to that. Why do you think this is important, and how do you suppose we could go about developing a better understanding of it?” We have all experienced situations where an apparently misguided question turned out to be far better than we thought.

Of course, there are situations where there is not sufficient time or energy to pursue the unknown. Perhaps the clinical workload is simply too great to do anything but answer each clinical question as correctly as possible. But even in these cases, questions can be remembered or recorded for revisiting at a later time.

A corollary is the danger of allowing clinical workloads—or for that matter, administrative, educational, or even investigative workloads — to become so burdensome that they effectively eliminate all possibility for taking time to ponder and hypothesize. When this happens, the radiologist gives up all hope of discovery. To wonder "is the anlage of progress in medicine” [5].

Embracing the unknown stands in a venerable educational tradition that stretches all the way back to one of the greatest educators of all time, Socrates. The famous but often misunderstood "Socratic method" is intended to be not a means of reducing learners to tears, but a way of helping both educators and learners recognize the limits of what we know. 
To confine education strictly to the known is to undermine freedom of thought. It says that all the questions worth posing have already been posed, and all the correct answers have already been found. Socrates knew that, given the limitations of the human psyche, such a state can never be reached, and in fact the opportunity to inquire is one of life's great blessings.

Socrates was inviting his "students" not to memorize what he said, but to learn to think for themselves, and to discover how delightful and enriching the pursuit of deeper understanding can be. From a Socratic point of view, the key feature of great educators is not how much they know but how well they can inspire others to pursue understanding.

Teaching the known has an important role to play, but we believe that radiological education, currently dominated by the multiple-choice test, has shifted too far in this direction. To achieve a better balance, educators who understand the power of the unknown need to redouble their efforts to introduce and reinforce the habit of asking good questions 


\section{References}

1. Dyche L, Epstein RM. Curiosity and medical education. Med Educ 2011;45:663-8.

2. Wu H. The role of open-ended problems in mathematics education. Journal of Mathematical

Behavior 1994;13:115-28.

3. Felder RM. On creating creative engineers. Engineering Education 1987;77:222-7.

4. Allen M, Berkowitz S, Hunt S, Louden A. A meta-analysis of the impact of forensics and communication education on critical thinking. Communication Education 1999;48:18-30.

5. Barondess JA. Viewpoint: on wondering. Acad Med 2005;80:62-5. 